\title{
Preface
}

Il lettore, a questo punto, se sarà accorto de un pezzo che questo non è un trattato de metallurgia: la mia presunzione non giunge a tanto, "ma voix est faible, et même un peu profane"

Primo Levi [1]

This is the second volume of a book that covers the new field of Sustainable Materials Science and Environmental Metallurgy [2].

\section{Introduction and purpose of the book}

The detailed motivations for the book are explained in the preface and the first chapter of volume 1 . They are briefly reviewed here.

Materials are classically studied by materials science, an engineering science. Materials engineers make metals, cement, polymers, monocrystalline silicon in large, specialized plants or mills; they also work on the development of new categories, grades, structures tailored designed for new specific applications, which it is their duty to invent: the chip of a $5 \mathrm{G}$ mobile phone, the largest suspension bridge in the world, the textile worn by a world-class athlete, the foil of a racing sailboat, etc.

Materials are objects of a different kind from forces, fields or strings, of which physics talks about: indeed, materials are used to make the artifacts which populate the anthroposphere. They are also quite different from the artefacts themselves, such as tools, machines or automobiles, the finality of which is immediate and clear. Materials can be used to make very many artifacts, all of them as a matter of fact, and therefore their finality is diverse.

\footnotetext{
${ }^{1}$ The original quotation says chimica, not metallurgia.
} 
Economics speak about intermediate goods or commodities to designate economic objects like materials, which stay hidden inside a value chain and, furthermore, are concealed below the surface of the artifacts: few people have a clear awareness of them, apart from designers and engineers. ${ }^{2}$

Close to materials in this twilight zone of public consciousness, one finds many chemical or metallurgical reactants, ${ }^{3}$ of which only process engineers have ever heard of, but also water and energy. People are more commonly aware of water, because it is also a consumer good, and of energy, because of its price and of its geopolitical importance demonstrated by its daily mention in the news.

Another category of economic objects ought also to be mentioned here, the common goods, which do not have a price, are not exchanged on a market and therefore are largely ignored or taken for granted: water belongs in this category again, when it plays an ecosystemic service, pollination and air, breathed or fueling a flame. ${ }^{4}$

Materials have a long temporality, which extends over cosmological time $(10 \mathrm{~Gy})$ from the explosion of large mature stars that disperse iron and other elements into the universe, to the formation of planetary systems, where metals are segregated in telluric planets like Earth in the core, as metals, and in the mantle as sulfides and oxides (4.5 Gy). Then geology plays its role reorganizing elements and eventually producing deposits of commercially important elements, at its own pace ( $3 \mathrm{~Gy})$, which is also commensurate with the pace of life (evolutionary time (1 Gy)). This is reviewed in volume $\mathbf{1}$, chapter 2 . Then, time focuses on the time of homo and of sapiens (1 My) to be followed by historical time $(10 \mathrm{ky})$, when material production and use started and developed to its present sophistication (volume 1, chapter 3 ). Future time is discussed in chapter $\mathbf{9}$, at the end of the present volume 2 .

Materials also extend beyond the anthroposphere, as they originate from the geosphere, in mines or quarries, Materials extend beyond the realms of engineering sciences, as they have been ubiquitous in every artifact of the anthroposphere, since the beginning of time, homo's time: they are technical objects, familiar to engineers, but also social objects, which interrogates about their ontological nature, the roles they play in society and how they play it. Materials, as technical objects, are studied in chapters 2, 4 and 5 of volume 1. Materials as social objects are studied in the present volume, particularly in chapters 1,8 and 10. Materials also emit back to all the ecological spheres, biosphere, hydrosphere and atmosphere during their lifecycle. This complex connection to the ecological spheres is usually called the environmental footprint of the material.

\footnotetext{
${ }^{2}$ The general public cannot distinguish aluminum and steel, which are the two most common metals! Rarer and more exotic metals are simply ignored, in a physical sense, except for precious metals, which, most of the time, are not hidden.

${ }^{3}$ e.g. metallurgical coke, lime, dolomite, pet coke.

${ }^{4}$ or fishing stock or grazing land. Common goods are rivalrous and non-excludable.
} 
Materials call on large materials and energy resources, because they are not naturally available in the form and structure that society needs them to be. Note, hic et nunc, that materials are out of equilibrium with nature: they revert back to equilibrium by the phenomenon of corrosion (chapter 5, volume 1). The art of giving them their commercially useful structure and quenching them there, in a metastable state, is called process or extractive metallurgy (volume $\mathbf{1}$, chapters 3 and 6 ).

Materials have to be concentrated, purified or reduced from natural resources called ores or minerals: that disperses a large burden of waste along the value chain, starting in the mine. Chapter 7 of volume 1 reviews this connection with the geosphere. Then society steps in, as the economy is veering back to a circular economy ${ }^{5}$ : this phenomenon is described and analyzed in volume 1 , chapter 8 .

To wrench materials from "earths" into their useful persona, i.e. steel from iron ore or aluminum from bauxite for example, fairly large amounts of energy are needed: to break chemical bonds, like the metal-oxygen bonds in oxide ores, heat metallurgical reactors to temperatures, where reactions take place at equilibrium - unless electrochemistry is called to the rescue, and provide for heat losses and other irreversibilities. This is discussed in volume $\mathbf{1}$, chapter 8.

The objective of the second volume is to tread into more unconventional dimensions of materials:

- discuss the connection of materials with the present major environmental threats, Climate Change (chapter 2), collapse of Biodiversity (chapter 3) and Pollution (chapter 6);

- explore their relationship with occupational and public health, but also toxicology, ecotoxicology and epidemiology and ecoepidemiology (chapter 5);

- Social Science offers fascinating approaches to materials, like the Actors Network Theory; there are also quantitative treatments based on applied tools like LCA (chapters 1, 4 and 8);

- finally, reverting back to a diachronic vision of materials focused on the recent past ( (chapter 5), recent geopolitics of materials) or in the future (foresight, chapter 9). The final message is that materials entertain a special connection with space and time, from the dynamics of stars and prehistory until tomorrow (chapter 10).

${ }^{5}$ There is a strong narrative today of moving the economy back from the linear to the circular economy, especially in political circles, as part of the European Green Deal for example. However, the circular economy was the reference model in most of the historical past: only the frenzy for high tech goods, based on the functional properties provided by rare elements, caused a temporary switch to a linear model for this very visible part of the world economy. In the background, most materials, like metals, paper or glass, were improving their act in the circular economy. 


\section{Organization of the book}

The book is organized in a series of chapters presented in two volumes.

There are nine chapters in the first volume of the book.

Volume 1 presents the theoretical framework for bringing together all the dimensions of materials, based on the model of the Spheres of Industrial Ecology, Anthroposphere, Biosphere and Geosphere. It then focuses on the connections of materials with the physical world, as analyzed by physics and engineering sciences, thus exploring the matters of resources and energy. A time dimension is also included in as far as the origin of materials and of the major elements of which they are made is explained from the viewpoints of cosmology (nucleosynthesis), geology (metallogenesis) and history, including prehistory; also stressed is the role that materials played in the emergence of civilizations and cultures.

There are 11 chapters in the second volume of the book, which deals with the interactions of the ecological spheres with society, thus life and the biosphere as affected by anthropogenic activities $[3,4]$. It also explores contributions from SSH disciplines, from philosophy and ethics to anthropology and sociology and addresses the matter of temporality in connection with foresight, futures and future studies.

- Chapter 1 - The special role that metals like steel or copper play in the energy system

Materials - and metals most especially - play a particular role in the structure of the energy system: for example, electricity could not be transported without the lines, cables, pipes, pylons, boilers, electrical machines that give the energy system its physical structure that would not exist without copper or steel. In a holistic, value-chain approach, materials thus have a societal role in making the present technological episteme and its energy subsystem possible: materials, beyond their usual role for which they are exchanged on a market, thus furnish ecosystemicanthropogenic functions and services, which are similar, mutatis mutandis, to the ecosystemic functions and services delivered by biodiversity.

- Chapter 2 - Materials, GreenHouse Gas emissions and Climate Change Two major environmental challenges are presently facing mankind: Climate Change and the collapse of Biodiversity.

Climate Change in connection with mankind has been present since the Neolithic Age, but it accelerated tremendously from the beginning of the 20th century and even more from its second half. It is clearly due to anthropogenic emissions of greenhouse gases, mostly $\mathrm{CO}_{2}$ and to a lesser extent $\mathrm{CH}_{4}$ and other gases, which originate mainly from the use of fossil fuels. Therefore, the anthroposphere has to find solutions to bring the phenomenon under some control. Energy-intensive industries are responsible for a small amount of emissions, which, however, is a significantly important part of industry emissions, and, therefore, low-carbon solutions and technologies need to be explored and eventually developed. 


\section{- Chapter 3 - Biodiversity and Materials}

The connection between materials and biodiversity is more complex than that with Climate Change and therefore it is more difficult to identify business and industrial strategies and policies that could be implemented to mitigate the phenomenon of biodiversity degradation. Biodiversity suffers both from Climate Change and from the increased footprint of mankind on Earth related in particular to urbanization.

- Chapter 4 - Holistic tools to deal with materials: LCA, MFA, SAT, etc. Materials are used to make durable goods, which remain in the anthroposphere for long periods of time (people's, consumers' or users' time, not the time of reversion to equilibrium with nature) and end up in waste which may or may not be recycled. This is captured by existing methodologies like Material Flow Analysis (MFA) or Life Cycle Assessment (LCA), especially their dynamic versions like dLCA (dynamic LCA), but also by emerging concepts like the Social Value of Materials (SOVAMAT) or the Sustainability Assessment of Technology methods (SAT).

Rather than a posteriori acknowledging the drawbacks of technologies or products, when the harm is done, more pro-active methods are being preferred: ecodesign, recycling, reuse and the many lean and frugal technologies.

\section{- Chapter 5 - Materials and Health.}

At the boundary between the anthroposphere and the biosphere exchanges take place between artefacts and life, plants, animals and people, which cover the fields of health and safety in the working place, public health, toxicology and ecotoxicology, epidemiology and eco-epidemiology. This analyzes the boundary interface at the microscopic scale of biological processes.

Chemicals and materials play subtle roles in these areas.

The chapter will provide an introduction and a review of the relevant issues. The COVID-19 pandemic, which is raging at the time of printing, helps explore the connection between health and environmental issues, including the collapse of biodiversity, as related to the shrinking of natural space.

- Chapter 6 - Local \& global environmental issues: emissions \& pollution. The other interface between the anthroposphere and the biosphere takes place at larger scales, geographical or global, regional and even planetary. Climate Change is an example, which is completely Global.

Making materials means selecting useful elements from raw materials and rejecting useless ones from the gangue as waste, the legal term, but also as by-products or coproducts, a resource-oriented expression. The gangue may be as much as one order of magnitude larger than the economically useful materials for common metals but several orders of magnitude for precious ones $\left(10^{6}\right.$ or more $)$. Moreover, minor compounds of high toxicity may also be generated and report back to the atmosphere, 
the hydrosphere or the geosphere, in what are called emissions to air, water or soil. In vernacular language, these are simply referred to as pollution. Waste generation and emissions are restricted by regulation and legislation. Technologies for dealing with environmental issues or for abating emissions (e.g. dust collection systems, low- $\mathrm{CO}_{2}$ emission technologies, combustion of Volatile Organic Compounds (VOC), etc.) are listed in Best Available Technology (BAT) documents.

Given the increasing magnitude of the footprint of the anthroposphere on Earth, many pollution issues which used to be considered as local have turned regional, transcontinental and even global. This means that in the future the regulatory targets for all emissions will drop by one or even two orders of magnitude. This will affect the material sectors and require the development of abatement technologies far more powerful than those available today.

- Chapter 7 - History, geography and geopolitics of Materials

Materials have been produced since the dawn of history and, along this timeline, a long series of different organizing principles have been at play to make materials available. The chapter gives an overview of how this organization has evolved, since the time of the hunter-gatherers until today. Then the various materials sectors are described in their present and modern avatars, with a foresight projection: where are these trends leading?

\section{- Chapter 8 - Philosophy and social science views about materials}

Materials viewed by historians, industrial producers, scientists and engineers are described in a way that brings together the various narratives given in the previous chapters and ties them up with the approaches of sociologists and philosophers. Indeed, while materials provide the boundaries between the technosphere, the biosphere and the part of the anthroposphere where people live, with strong property gradients separating systems with very different physicochemical conditions, they also constitute the infrastructure in which people live and the technological episteme in which they operate. This ensures its robustness, resilience and extension in time. Moreover, materials exhibit ontological features, offering the same services across historical periods of time on the basis of classes of materials which have remained the same almost since prehistory. Of course, their microstructural complexity, the precision of their composition and of their properties and their level of purity have changed with the complexification of society. And newer materials are continuously adding to the biodiversity of materials, but without replacing the older ones.

\section{- Chapter 9 - Foresight about material}

What does the future have in stock as far as materials are concerned? A certain continuity, but also explosions of creativity, whenever a challenge is raised, which requires material innovation. Can steel or copper 
production in 2030, 2050 be predicted? When will peak steel or peak concrete levels be reached, assuming this kind of concept makes sense? On what kind of modeling are these projections based? Where does the uncertainty lie, for example regarding the sensitivity to Climate Change, one of the major disruptors for the future?

- Chapter 10 - Conclusions - materials in space and time

Materials are not simply technological constructs: they are also to a large extent social constructs. Two sides of a complex, dialectical reality, as materials belong to both worlds. Thus, the case for a broader vision of materials than that provided by material science has been made throughout the book and the connection between materials, society and nature, thus between the spheres of natural and industrial ecology, ought to be taught to students. We propose to name the field Sustainable Materials Science or Environmental Metallurgy.

- Chapter 11 - Materials, COVID-19 and sanitary risks

Chapter 11 was added in May 2020, when the book was already in the hands of the publisher, because the COVID-19 pandemic had started to wreak havoc in the world. Indeed, the sanitary crisis had already brought the economy to a halt, placed most people under lockdown and triggered an economic and social crisis. The consequences were being felt in every nook and cranny of society, including in the world of materials - hence the need for an extra chapter. Understanding what was happening in real time and writing about it without the hindsight brought by widespread academic analysis was a challenge, more like writing a press review than a scientific one. Therefore this 11 th chapter can be viewed as an attempt to tackle a crisis that surfaced suddenly and unexpectedly and to verify whether the methodology proposed in the book gives the keys to propose a narrative, if not an understanding of the connection between the pandemic and materials.

\section{Other itineraries to explore this book}

The book was built around the rationale of the Spheres of Industrial Ecology.

There are other ways to explore the book, therefore other itineraries that can be followed by the reader who wants to keep tract of a specific subject, disciplinary approach or material. They will be shown at the beginning of each chapter under the label of reading itineraries.

The various disciplines handled in the 10 first chapters are shown in Table 1 to Table 2. A dark cell indicates that the discipline is more heavily discussed in a particular chapter.

A different series of itineraries, based on the kind of materials that is the particular topic of a chapter, is given in Table 3 to Table 4 . 


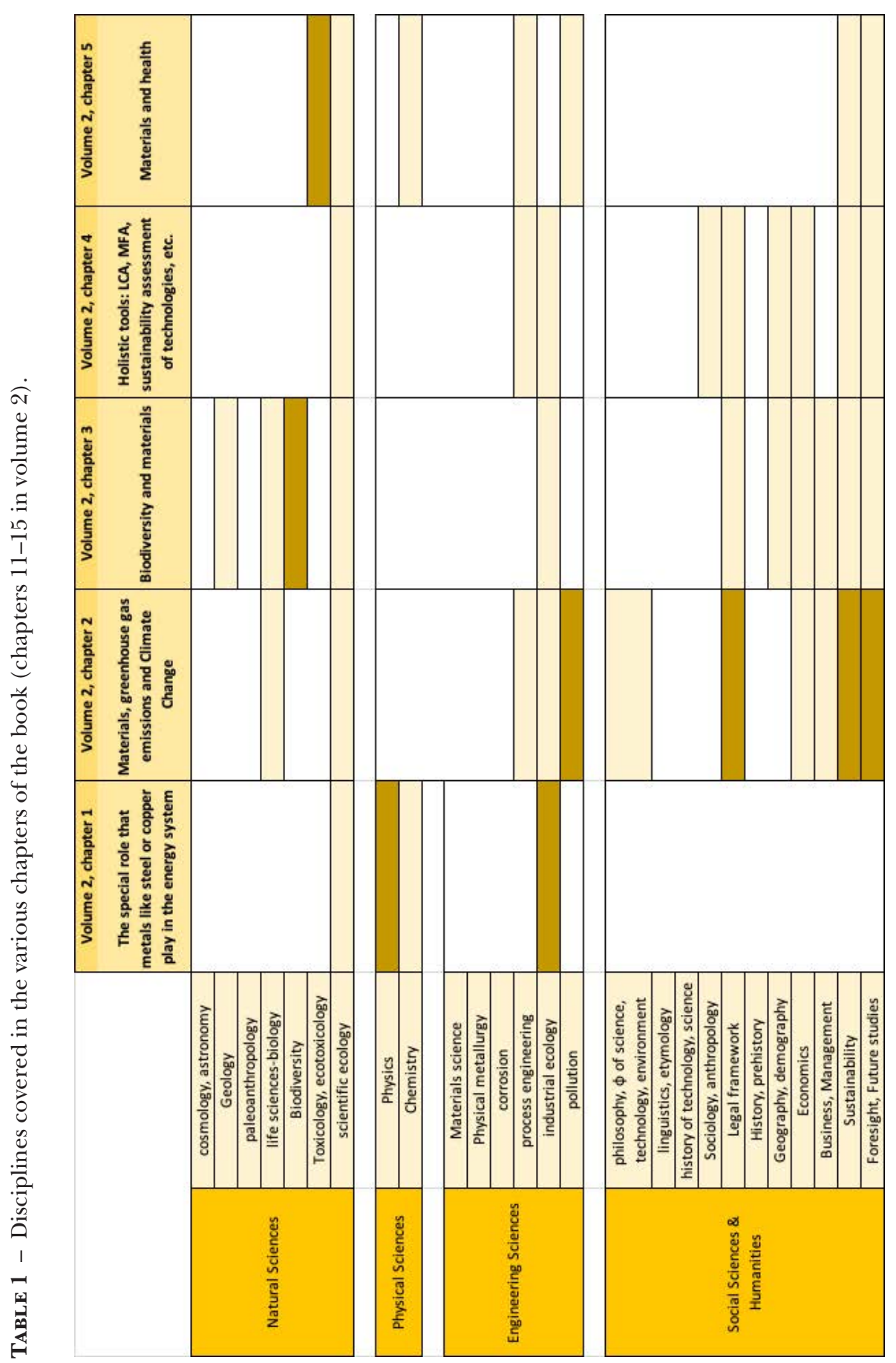




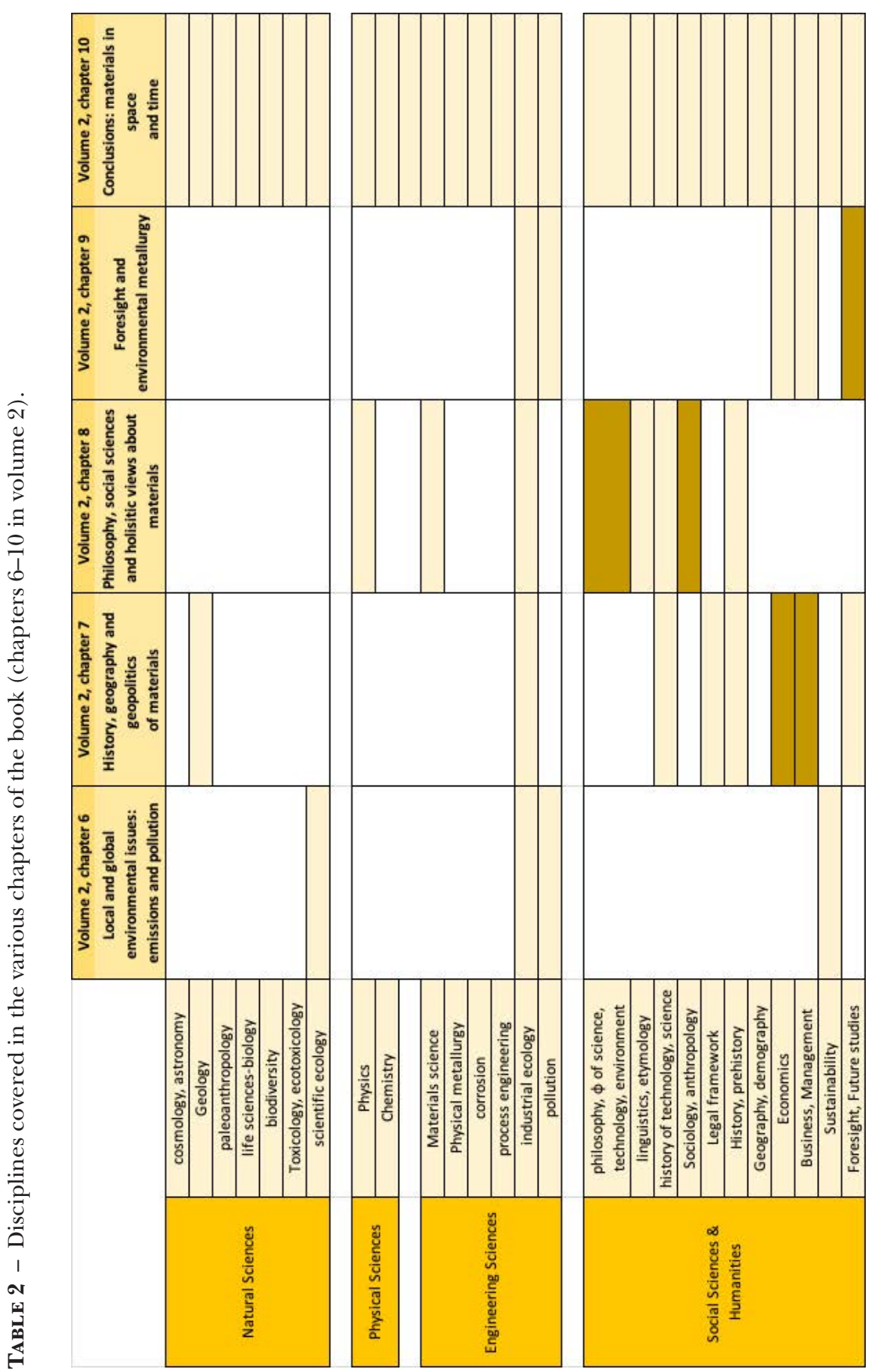




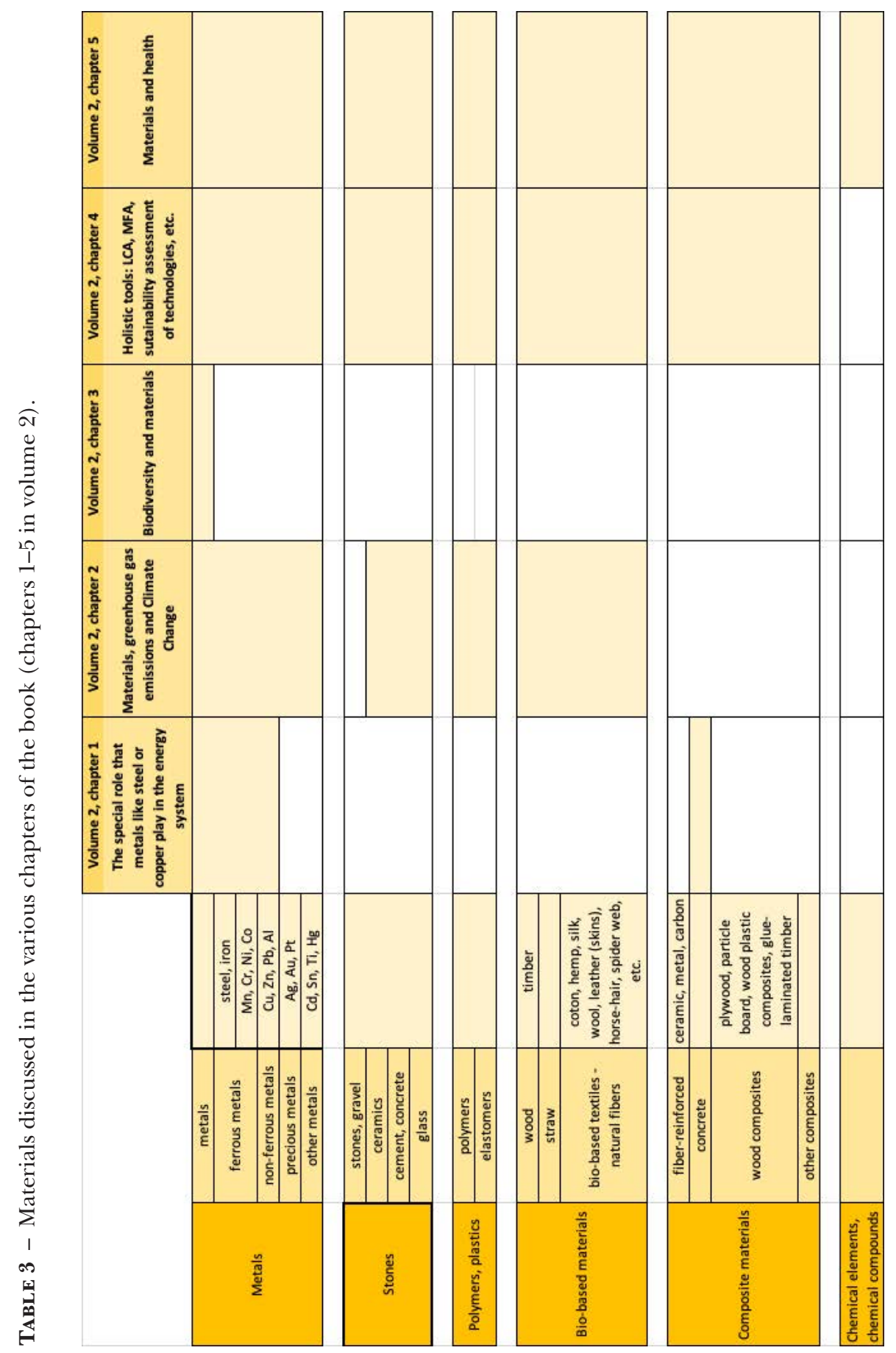




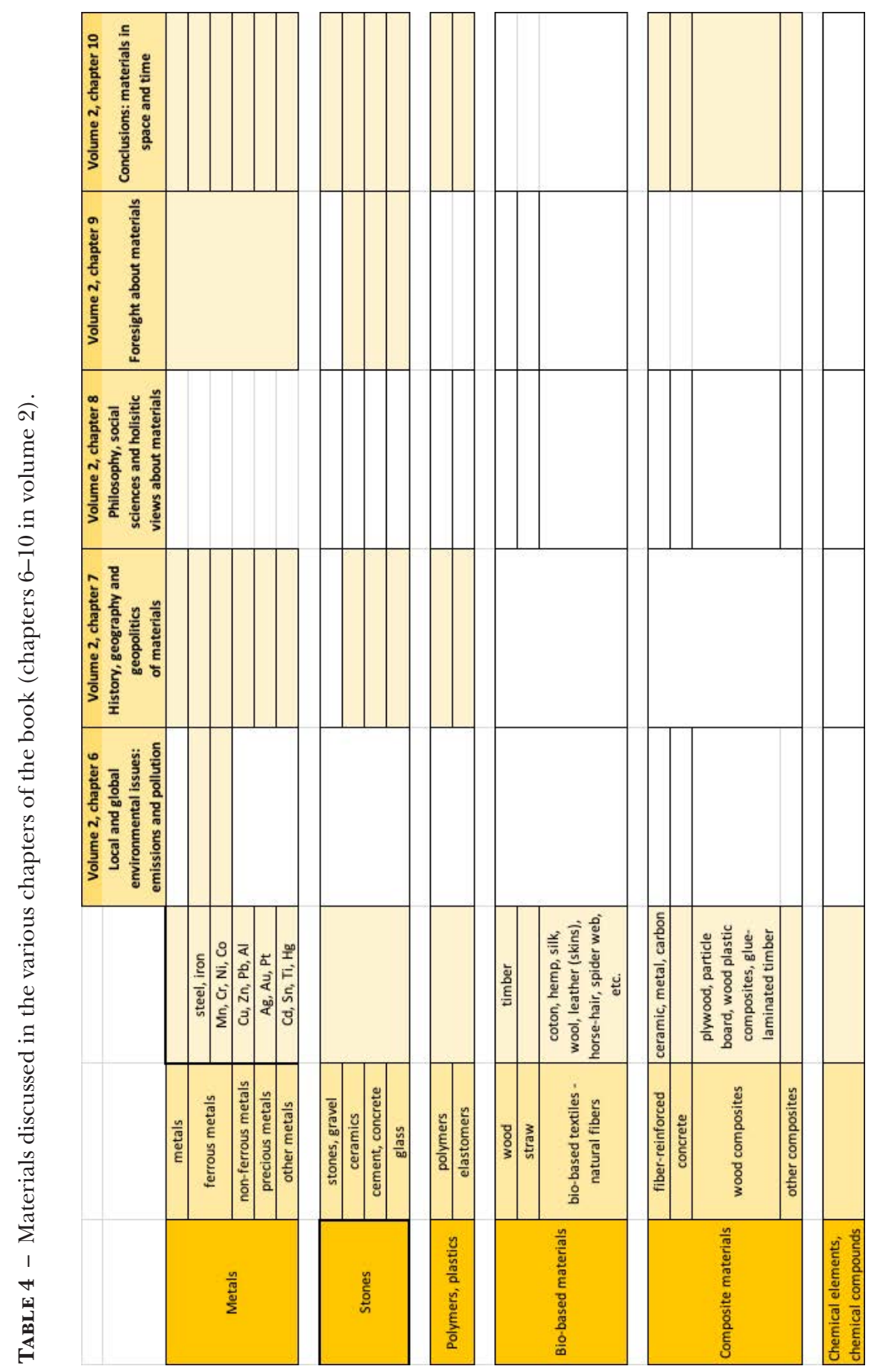




\section{References}

[1] Levi P. (1973) Carbonio, Il sytema periódico. Guilio Einaudi, Torino.

[2] Birat J.-P. (2020) Sustainable Materials Science - Environmental Metallurgy, Volume 1 - Origins, basics, resource and energy needs. EDP sciences, Les Ulis, France, 476 pages.

[3] Conejo A.N., Birat J.-P., Dutta A. (2020) A review of the current environmental challenges of the steel industry and its value chain, J. Environ. Manage. 250(109782), 9.

[4] Birat J.-P. (2020) Society, materials and the environment: the case of steel, Metals 10(331), 36, doi: 10.3390/met10030331. 